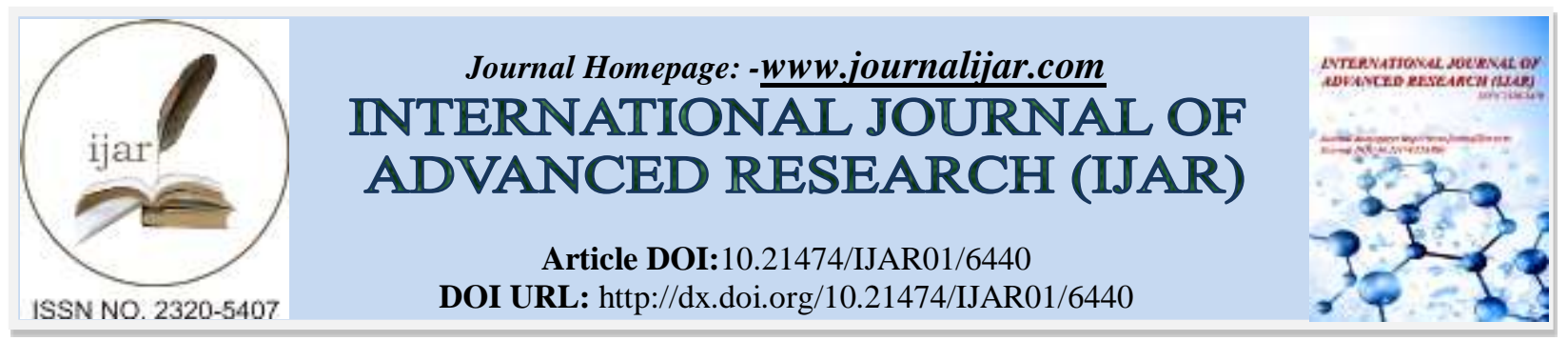

RESEARCH ARTICLE

\title{
COMPARATIVE STUDY OF TWO DIFFERENT PROCEDURES FOR PRIMARY HYPOSPADIAS REPAIR.
}

\author{
Abdulraheem Ali bakheet ${ }^{1}$, al-Gaysi Sami Hamad ${ }^{2}$, Oleiwi Masaoodi ${ }^{3}$ and Faris M. AL-badran ${ }^{3}$. \\ 1. (F.I.M.S) special urologist urological Department AL-karama Teaching Hospital. \\ 2. (F.I.M.S) special urologist urological Department AL-Karama Teaching Hospital. \\ 3. (F.E.B.U,F.I.M.S) AL-Hussain teching hospital, Karbala, Iraq.
}

\section{Manuscript Info}

Manuscript History

Received: 04 December 2017

Final Accepted: 06 January 2018

Published: February 2018

Keywords:-

Hypospadias, Iraq, Mathieu, Repair, Snodgrass.
Abstract

Background: Different modalities of procedures for hypospadial repair have been described in the literature. Data about the outcome of two main different procedure of repair are scares from Iraq. The aim of this study is to compare the results of these two methods of hypospadias repairs. The present study compared two single stage hypospadias repairs, namely, tubularized incised plate (Snodgrass) repair and Mathieu's repair.

Methods: It involved 50 patients diagnosed with penile hypospadias, from March 2011 to April 2015 at the Department of Surgery, AlKarama Teaching Hospital. After a detailed history, local examination was performed with reference to the site of meatus, shape of glans, and presence of chordee, patients were randomly assigned as Group A of 26 patients in whom Snodgrass repair was accomplished and Group B having 24 patients in whom Mathieu's repair was performed. On follow-up, the patients were examined for the position of meatus, shape of meatus, urinary stream, urethra-cutaneous fistula, and stricture formation.

Results: The results showed that the mean age of presentation was $7 \pm 6$ years (range 1-13years). The mean operative time was $90 \pm 15$ (75-105) minutes and 60 \pm 15 (45-75) minutes in Snodgrass and Mathieu's repair respectively. Complications after surgery were urethero-cutaneous fistula in $2(7.69 \%)$ and $4(16.67 \%)$, meatal stenosis in $1(3.84 \%)$ and $2(8.33 \%)$, wound infection in $4(15.38 \%)$ and $3(12.5 \%)$ cases in Snodgrass repair and Mathieu repair, respectively, wound dehiscence was equal in Snodgrass repair and Mathieu repair.

Conclusions: It can be concluded that the cosmetic results were excellent with Snodgrass repair with a normal looking slit like meatus.

Copy Right, IJAR, 2018,. All rights reserved.

\section{Introduction:-}

Hypospadias is a congenital defect due to incomplete tubularization of the urethral plate leading to abnormal location of the meatus anywhere along the ventral aspect of penile shaft and down on to the perineum. In the majority of cases (over $80 \%$ ), the meatus is located distal to the midshaft. 
The objective of this study was to surgery in hypospadias is to achieve a functional penis with a normal cosmetic appearance. The commonest repairs to correct distal hypospadias are the Thiersch-Duplay, Mathieu, Mustarde, meatal advancement and glanuloplasty (MAGPI) and tubularized incised plate (TIP) urethroplasty. ${ }^{1-4}$ Of these procedures Mathieu and Snodgrass urethroplasty (Snodgrass repair) have been widely practiced. Snodgrass being now the preferred method since it creates a vertical slit-like normal appearing meatus, unlike a horizontally oriented and rounded meatus ('Fish mouth') produced by the meatal based (Mathieu) flap repair. This procedure allows construction of neourethra from the existing urethral plate without additional skin flaps. The technique is versatile and suitable for almost all distal lesions. ${ }^{5}$

Both Mathieu and Snodgrass make use of the urethral plate which makes the appearance to near natural.6The choice between the procedures depends more on surgeon's experience rather than scientific evidence. The study aims to compare the results of these two methods of hypospadias repairs.

\section{Methods:-}

A prospective follow up study was done for the period extended between March 2011 and April 2015. A total of50 patients with primary distal hypospadias were recruited for this study. The patients were randomly as signed as Group A of 26 patients in whom Snodgrass repair was accomplished and Group B having 24 patients in whom Mathieu's repair was performed. The previously operated cases of distal penile hypospadias with extensive scarring, severe chordee likely to necessitate a staged procedure, and patients with micro penis with poorly developed urethral plate and urethral groove were excluded from the study. Repair of the hypospadias was done under general anesthesia and endotracheal intubation.

In Snodgrass repair, a segment of the urethral plate $8-10 \mathrm{~mm}$ wide was marked out distal to urethral meatus and incision was made along the lateral borders of the urethral plate. An incision was made sub-coronally and was completed ventrally as "U" shape proximal to urethral meatus. After carefully degloving the penis, granular wings were adequately developed lateral to the urethral plate. A midline vertical incision was made with a knife in the urethral plate. The neourethra was reconstructed around 6 or 8 Fr catheter using multiple interrupted sutures with polyglycolic acid (Vicryl No. 6- sutures with knots inside. Glanuloplasty was performed with 6-0 polyglycolic acid (Vicryl) in two layers. Meatoplasty and skin cover were completed.

In Mathieu's repair, the urethral plate and perimeatal based flap were marked. Typically, the width of $7.5 \mathrm{~mm}$ was measured for the proximal flap. Longitudinal lines outlining the urethral plate were then drawn extending along the length of required flap. Urethral plate and proximal shaft skin were incised about 7-8 $\mathrm{mm}$ wide and the penis was degloved after sub-coronal circumferential incision. Granular wings were developed by deep dissection under glans to perform tension free glanuloplasty. Proximal shaft skin flap was mobilized and transposed toward the urethral plate. This flap was folded over the urethral meatus and neourethra formed over 6 or 8 Fr tube wit interrupted 6-0 polyglycolic acid (Vicryl) knots inside. Glanuloplasty and skin coverage completed the procedure. In both the groups chordee was managed by degloving of penis.

Dressing of the penis was first opened 5 days after surgery, and the wound was laid open. The catheter was removed 7 to 14 days postoperatively; patients were discharged home. Patients were examined in follow-up weekly for the first month, four weekly for next 6 months, 3 monthly for next year, and thereafter 6 monthly. The mean follow-up of the patients was 17 months, ranging from 1 to 44 months in both the groups.

Data were entered and analyzed by computer using the available software (SPSS-24; Statistical Packages for Social Sciences-version 24). Data were presented as mean, standard deviation, and range with the available statistical test of significance of Students-t-test for difference between two independent means or Pearson Chi-square test for difference between proportions. $P$ value equal or less than 0.05 was considered as the level of significance.

\section{Results:-}

The mean age $7 \pm 6$ years (range between 1-13years). The difference in the age groups was statistically not significant between the two groups. Coronal hypospadias was present in $25(50 \%)$, sub-coronal hypospadias $20(40 \%)$ and distal penile in $5(10 \%)$ patients. 
Mathieu repair was performed in $24(48 \%)$ patients and tubularized incised plate (TIP) urethroplasty (Snodgrass procedure) in the rest of $26(52 \%)$ patients. Urethral plate was healthy in all patients. Pre-surgical hormonal treatment was not given to any of our patients. Operative time ranged from 45 to 75 minutes (Mean=60 \pm 6.7 minutes) for Mathieu group and 75 to 105 minutes (Mean=90 \pm 7.1 minutes). Hospital stay was 48 hours to 5 days (Mean=3 days) for Mathieu repair and 48 hours to 4 days (mean 2.5 days) for Snodgrass repair.

The difference in the operative time between the two surgical procedures was statistically significant (Table 1). Meatal stenosis developed in 1 (3.84\%) and $2(8.33 \%)$ patients in Group A and Group B, respectively, meatal stenosis was managed by dilatation and one patient from each group needed meatoplasty. Urethrocutaneous fistula developed in $2(7.69 \%)$ patients of Group A and $4(16.67 \%)$ patients in Group B. Wound infection developed in 4 $(15.38 \%)$ and $3(12.5 \%)$ patients in Group A and Group B, respectively, and was managed by antibiotics.

On follows up the cosmetic appearance of the penis was excellent in 24 (92.31\%) patients in Group A; in Group B excellent cosmetic was achieved in $10(41.67 \%)$ patients in addition 8 (16.7\%) patients in Group B had mild torsion of the shaft compared to none in Group A $(\mathrm{P}=0.0001)$, these differences were statistically significant between the two groups $(\mathrm{P}=0.0001 \& 0.0001$ respectively). The shape of meatus was slit like and vertically oriented in $23(88.46 \%)$ patients who had undergone Snodgrass repair while it was round and regular in $20(83.33 \%)$ patients who had undergoneMathieu's repair $(\mathrm{P}=0.602$; Not significant statistically), also chordee was seen in 13 (50\%) patients in Group A and 11 (45.83\%) in Group B (P=0.768; Not significant statistically).

Table 1:- The operative time and complications findings of the two groups.

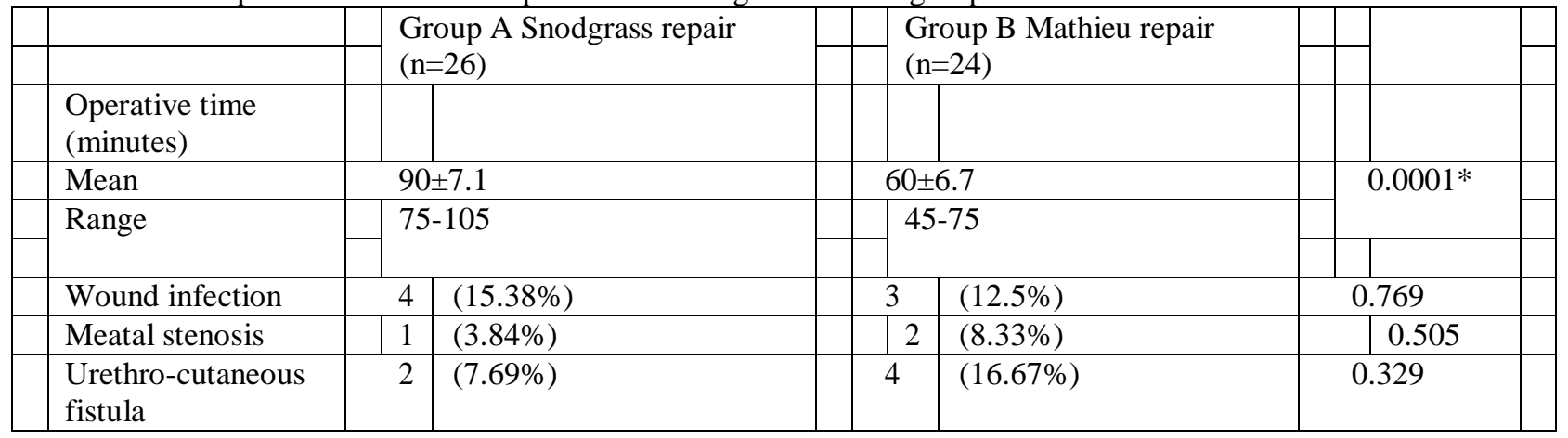

*Significant difference between two independent means using Students-t-test or significant difference between proportions using Pearson Chi-square test at 0.05 level

\section{Discussion:-}

Hypospadias is a common clinical problem with an incidence of $0.8-8.2 / 1000$ live male births. ${ }^{7}$ In the majority of cases abnormal meatus is situated in the glanular, coronal or in the distal part of the shaft.

The main goal of any hypospadias repair is to achieve a functionally and cosmetically normal penis. Even in the hands of most experienced surgeons, hypospadias repair is associated with a number of complications ranging from urethra-cutaneous fistula to the complete breakdown of neourethra requiring total reconstruction of the different single stage hypospadias repairs. The Snodgrass repair urethroplasty and Mathieu's repair have been widely practiced. Final cosmetic results and normal penile functioning are two important considerations in hypospadias surgery.

This technique was first described by Mathieu for distal hypospadias using ameatal based flap. ${ }^{8}$ Then Wacksman reported his initial experience with this technique. ${ }^{9}$ Subsequently, Rabinowitz described catheterless repair using the Mathieu repair. ${ }^{10}$ Although 1 and 2-layer neourethral anastomoses have demonstrated satisfactory results, the twolayer technique has produced lower complication rates. ${ }^{11}$

Careful preservation of the vasculature of the flap and avoidance of overlapping suture lines produce a watertight closure with minimal risk of postoperative fistula formation. Mathieu repair also provides good functional results but cosmetic is more preserved in Snodgrass repair. Minimal complication rate has been reported even with stent 
less repair. ${ }^{11}$ Even now, Mathieu procedure is considered as the standard by some surgeons, for distal hypospadias. ${ }^{2,9,11}$ Rich et al incised the urethral plate in the midline to improve cosmetic of a hypospadias repair. ${ }^{12}$

Later, Snodgrass advanced this concept by extending the incision of the urethral plate from the meatus to the tip of the glans.4This maneuver allowed construction of anew urethra from the existing urethral plate. It was suggested that healing may occur through re-epithelialization of the relaxing incision without obvious scarring, allowing the incised edges to remain separated. ${ }^{13}$

Today Snodgrass repair urethroplasty has become a preferred method for repairing distal hypospadias because of its versatility, to correct different meatal variants, the simplicity of the operative technique, low complication rate and reliable creation of abnormal appearing granular meatus. ${ }^{14}$ Severe chordee and unhealthy urethral plate are the two limiting factors for this procedure. Fistula can be avoided by interposition of a vascularized dates flap between the neourethra and overlying skin.

Recently Cheng et al have suggested a two-layer closure of the neourethra to minimize the fistula rate. ${ }^{15}$ Meatal stenosis is mostly the result of technical error; not confining the dorsal midline incision to the urethral plate. Other complications such as urethral stricture, diverticulum, and wound breakdown are infrequent. Excellent cosmetic results have been reported with $0.5 \%$ meatal stenosis, $1 \%$ uro-cutaneous fistula and rate of re-operation $1.5 \%{ }^{7}$

Rabinowitz has reported the complication rate of $13.5 \%$ in stent less Mathieu repair. ${ }^{10}$ Hakim et al compared the results of the Mathieu procedure with and without a catheter and reported complication rate of $2.7 \%$ in stented and $3.6 \%$ in unstented repair.

However, Buson et al noted a significantly higher complication rate of $18.9 \%$ in stentless versus $4.6 \%$ in stented cases. ${ }^{16}$ In this study there is a significantly high rate of fistula formation with Mathieu repair than in Snodgrass repair $(7.7 \%$ versus $3.3 \%)$. Other

complications like wound breakdown and meatal stenosis are equally frequent in both the procedures. Stricture formation is also slightly more common in Mathieu group (3.3\% versus 2.2\%). These results are comparable with other similar studies.

In one similar comparative study, 17 wound dehiscence and flap necrosis have been seen more frequently with Snodgrass repair group with no difference between groups regarding fistula formation and total success rate similar (78.6\% in Snodgrass repair and $77.8 \%$ in Mathieu repair group).

While the mean duration of surgery was reported to be significantly lower for Snodgrass procedure than for Mathieu repair (75 versus 115 minutes) $(\mathrm{P}<0.05)$ with urocutaneous fistula more frequently in Mathieu repair and meatus being slit like in Snodgrass repair and rounded and horizontalin Mathieu repair. ${ }^{18}$

In another study both the procedures were combined to avoid the risk of de-vascularization of the neourethral flap. ${ }^{19}$ Another study has shown the comparison and it has been concluded that the operative time and complication rate was less than Mathieu repair and had better cosmetic results producing a slit like normal looking meatus. ${ }^{18}$ In this study the same findings have been observed.

In this series, chordee was seen in $13(50 \%)$ patients in Group A and $11(45.83 \%)$ in Group B ( $\mathrm{P}=0.768$; Not significant statistically). Incidence of chordee was different in different series; it was $35 \%$ in Sweet et al, series, $100 \%$ in Tonvichien and Niramis case series, and $19.9 \%$ in Singh et al. series of cases. ${ }^{7,20,21}$

The meatal based flap is commonly used urethroplasty for distal penile hypospadias; the reported complication of Mathieu's urethroplast is between 5 and $21 \%$ for distal penile hypospadias. There is also an increased risk of meatal stenosis because there is reduced blood flow to the distal part of the flap. ${ }^{22}$ Other potential problems of peri-meatal based flap are hair growth at meatus and cosmetically undesirable horizontal and rounded meatus. The concept of incising the urethral plate enables tubularization and creating a neourethral tube irrespective of the glans configuration or the location of the meatus. ${ }^{18}$ This deep incision does not compromise its viability and reepithelialization of neourethra as compared to Mathieu's in which two suture lines are needed on two sides. In TIP 
repair, only one suture line is used in creating a neourethral tube. TIP repair was done in significantly shorter time than Mathieu's repair which has also been described by Oswald et al and Guo et al. ${ }^{18,23}$

In this series, complications were seen in $16(32 \%)$ patients. The complications included wound infection seen in 4 $(15.38 \%)$ patients in the group-A and $3(12.5 \%)$ patients in the group-B. Complications do occur after every hypospadias repair.

In this series, excellent cosmetic was achieved in $24(92.31 \%)$ patients in the Group A and in the Group B cosmetic appearance was excellent in 10 (41.67\%) patients and 8 (16.7\%) patients had mild torsion of shaft. Our cosmetic outcome after Snodgrass repair urethroplasty was similar to that reported by authors like Anwar-Ul-Haq et al, Guo et al, and Imamoğlu and Bakirtaş. ${ }^{17,23,24}$

As evident in our series, the urethra-cutaneous fistula and meatal stenosis rate was more in Mathieu's group as compared to that of Snodgrass group. One explanation for this is the need for two suture lines in case of onlay flap technique on either side which might be jeopardizing the vascular supply of the flap. Cosmesis of penis is of concern to the parents which was best achieved with Snodgrass repair urethroplasty as compared to Mathieu's urethroplasty. Snodgrass repair creates a vertically oriented, slit like normal looking meatus which is cosmetically desirable.

\section{Conclusion:-}

Our study has revealed that Snodgrass repair urethroplasty has an edge on Mathieu's urethroplasty, so we recommend the TIP urethroplasty in all primary and distal cases of hypospadias. Snodgrass repair is associated with excellent cosmetic and few manageable complications. It offers a safe and reliable modality for primary repair of distal penile hypospadias. Cosmetic appearance of the external urethral meatus is highly satisfactory with Snodgrass repair urethroplasty.

Funding: No funding sources

Conflict of interest: None declared

Ethical approval: The study was approved by the institutional ethics committee

\section{References:-}

1. Ross MD, David FF. Distal hypospadias repair by the modified Thiersch-Duplay technique with or without hinging the urethral plate: a near ideal way to correct distal hypospadias. J Urol. 1999;162:1156-8.

2. Minevich E, Pecha BR, Wacksman J, Sheldon CA. Methieu hypospadias repair: experience in 202 patients. J Urol. 1999;162:2141.

3. Snodgrass WT. Tubularised incised plate hypospadias repair: indications, techniques and complications. Urol. 1999;54:6-11.

4. Snodgrass WT. Tubularised incised urethral plateurethroplasty for distal hypospadias. J Urol. 1994;151:46465.

5. Bath AS, Bhandari PS, Mukherjee MK. Repair of distalhypospadias by the tubularised incised plate urethroplasty: A simple versatile technique. Indian J Plast Surg. 2003;36:23-5.

6. Erol A, Baskin LS, Li YW. Anatomical analysis of the urethral plate: Why preservation of the urethralplate is import-ant in hypospadias repair. Br J UrolInt. 2000;85:728-39.

7. Sweet RA, Schrott HG, Kurland R, Culp OS. Study of the incidence of hypospadias in Rochester, Minnesota 1940 - 70, and a case control comparison of possible etiologic factors. Mayo Clin Proc. 1974:49:52-8.

8. Mathieu P. Traitementenun temps de l'hypospadiasbalaniqueoujuxtabalanique. J Chir. 1932;39:481-9.

9. Wacksman J. Modification of the one-stage flip-flap procedure for repair of distal penile hypospadias. Urol Clin N Am. 1981;8:527-33.

10. Rabinowitz R. Outpatient catheterless modified Mathieu hypospadias repair. J Urol. 1987;138:1074-82.

11. Hakim S, Merguerian PA, Rabinowitz R., Shortliffe LD, McKenna PH. Outcome analysis of the modified Mathieu hypospadias repair: comparison of stented and unstented repairs. J Urol. 1996;156:836-43.

12. Rich MA, Keating MA, Snyder H, Mc C III, Duckett JW. Hinging the urethral plate in hypospadias meatoplasty. J Urol. 1989:142:1551-3. 
13. Bleustein CB, Esposito MP, Soslow RA. Mechanism of healing following the Snodgrass repair. J Urol. 2001;165:277-89.

14. Snodgrass WT, Lorenzo A. Tubularised incised plate urethroplasty for proximal hypospadias. BJUInt. 2002;89:90-3.

15. Cheng EY, Vemulapalli SN, Kropp BP. Snodgrass hypospadias repair with vascularised dartos flap: The perfect repair for virgin cases of hypospadias? J Urol. 2002:168:1723-6.

16. Buson H, Smiley D, Reinberg Y, Gonzalez R. Distal hypospadias repair without stents: is it better? J Urol. 1994;151:1059-64.

17. Imamuglu MA, Bakirta H. Comparison of two methods- Mathieu and Snodgrass- in hypospadias repair. UrolInt. 2003;71:251-4.

18. Oswald J, Komer LI, Riccabona M. Comparison of the perimeatal-based flap (Mathieu) and the tubularized incised-plate urethroplasty (Snodgrass) in primary distal.

19. Kiss A, Nyirady P, Pirot L, Merksz M. Combined use of perimeatal based flap urethroplasty. Eur J Pediatr Surg. 2003;13:383-5.

20. Tonvichien L, Niramis R. Tubularized incised plate urethroplasty in hypospadias repair. Experience at Queen Sirikit National Institute of Child Health. J Med Ass Thailand. 2003;86(3):S522-30.

21. Singh N, Sharma E, Sharaf R, Goswamy HL. Tubularized incised plate urethroplasty (Snodgrass procedure) for distal penile hypospadias: a regional centre experience. Ind J Urol. 2005;21(2):109-11.

22. EL-Saket HM. Primary distal hypospadias repair: tubularised incised plate urethroplasty (Snodgrass) versus the perimeatal based flape (Mathieu’s) Egypt. Plastic Reconstruct Surg. 2004;28(1):56-61.

23. Guo Y, Ma G, Ge Z. Comparison of the Mathieu and the Snodgrass urethroplasty in distal hypospadias repair. Zhonghua Nan KeXue. 2004;10(12):916-18.

24. Anwar-Ul-Haq AU, Akhter N, Nilofer N, Samiullah S, Javeria J. Comparative study of Mathieu and Snodgrass repair for anterior hypospadias. J Ayub Med Col Abbottabad. 2006;18(2):50-2. 